\title{
Psychometric properties of the WHOQOL- BREF among next of kin to older persons in nursing homes
}

\author{
Helena Rosén *i(B, Gerd Ahlström(1) and Annika Lexén(1)
}

\begin{abstract}
Background: The worries of next of kin about their older loved ones in nursing homes can be extensive and can adversely affect their subjective experiences of their own physical, mental and social well-being. It is thus of utmost importance to measure the quality of life of next of kin in a valid and reliable way.

Methods: The design is a cross-sectional study with psychometric evaluation based on classical test theory in preparation for a planned educational intervention study on palliative care. An abbreviated version of the World Health Organization's quality-of-life self-assessment instrument WHOQOL, the Swedish WHOQOL-BREF, was completed by 254 next of kin of older persons in 30 nursing homes. Data quality was assessed via the mean, median, item response, missing values, and floor and ceiling effects. Reliability was estimated using Cronbach's alpha and corrected item-total correlations. Construct validity was estimated by Spearman's rank correlation, and model fit was assessed using confirmatory factor analysis.
\end{abstract}

Results: The rate of missing data was low (less than 2\%). Ceiling effects ranged from 11 to $43 \%$ and were above $20 \%$ for 21 of 24 items. The corrected item-total correlations varied between 0.35 and 0.68 and were thus well above the lower limit of 0.30 . Cronbach's alpha was 0.83 , indicating satisfactory internal consistency. The confirmatory factor analysis indicated a fair to close model fit (comparative fit index 0.93 , root mean squared error of approximation 0.06).

Conclusions: The findings suggest that the WHOQOL-BREF may constitute a reliable and valid measure of quality of life for use among next of kin to older persons in nursing homes. When interpreting the results, it is important to assess the ceiling effect, as it may restrict the ability of the WHOQOL-BREF to detect true positive changes in quality of life over time.

Trial registration: NCT02708498.

Keywords: Quality of life, Factor analysis, Confirmatory factor analysis

\section{Background}

In countries with an ageing population, it is a common situation for an older person to live in a nursing home due to multiple morbidities with complex medical and care needs [1]. These frail older people need round-the-

* Correspondence: Helena.Rosen@med.lu.se

Department of Health Sciences, Faculty of Medicine, Lund University, PO Box 157, SE-221 00 Lund, Sweden clock care for the remainder of their lives. Feelings of uncertainty and frustration among next of kin at admission is often related to experiences prior to the older person moving into the nursing home, and the initial period in the nursing home affects transition experiences for the next of kin [2]. The transfer to a nursing home means handing over a loved one into the care of the staff after a long period of providing care at home. Most next

C C The Author(s). 2020 Open Access This article is licensed under a Creative Commons Attribution 4.0 International License, which permits use, sharing, adaptation, distribution and reproduction in any medium or format, as long as you give appropriate credit to the original author(s) and the source, provide a link to the Creative Commons licence, and indicate if changes were made. The images or other third party material in this article are included in the article's Creative Commons licence, unless indicated otherwise in a credit line to the material. If material is not included in the article's Creative Commons licence and your intended use is not permitted by statutory regulation or exceeds the permitted use, you will need to obtain permission directly from the copyright holder. To view a copy of this licence, visit http://creativecommons.org/licenses/by/4.0/ The Creative Commons Public Domain Dedication waiver (http://creativecommons.org/publicdomain/zero/1.0/) applies to the data made available in this article, unless otherwise stated in a credit line to the data. 
of kin remain actively involved in caregiving but are stressed by uncertainties about how to interact with the nursing home staff [3-6]. As ageing progresses, with increasingly severe multiple morbidities, this interaction can become even more stressful for the next of kin which may have a negative impact on their quality of life (QOL) $[7,8]$. It may cause them to experience conflicting feelings of responsibility [9] between their own needs and those of their relative, as a result of taking part in the care while at the same time leaving the responsibility for care to the staff $[9,10]$ They often carry a heavy burden and may experience mental ill health [11]. They closely follow their loved one's transition until the end of life, which has an impact on their own health and leads to difficulties in managing their daily lives [12]. Nursing homes have become a major arena for the provision of palliative care and little is known about the QOL of next of kin's to older persons in nursing homes. Therefore, it is of utmost importance to measure their QOL in a reliable and valid way.

The WHO definition of QOL, applicable in this study, is a broad, multidimensional concept defined as individuals' perceptions of their position in life in the context of the culture and value systems in which they live and in relation to their personal goals, expectations, standards and concerns [13-15] (WHOQOL Group, 1995, p. 1405). The experience of QOL varies over time and in different life situations. In conjunction with the WHO promotion of the Health for All goal, which includes mental, social and physical well-being in diverse populations around the globe, the organization began constructing a QOL assessment instrument in early 1990 [13]. The first published instrument, the WHOQOL100, was developed for cross-cultural application and intended for international use. The instrument is based on 1) the WHO definition of QOL, 2) empirical evidence (such as focus groups with healthcare professionals, patients and healthy people) gathered by 15 international research centres representing different cultures and 3) statistical testing (such as test-retest reliability and structural equation modelling) demonstrating a fourdomain structure $[13,16,17]$. Although the WHOQOL100 provides a detailed assessment of individual QOL, it may be too lengthy for many respondents and less useful in a project where QOL is only one variable of interest $[16,17]$. The WHO group therefore constructed the WHOQOL-BREF, based on the most general questions from each of the domains of the WHOQOL-100 [17]. The four WHOQOL-BREF domain scores correlated highly (0.89 or more) with the original WHOQOL-100 domain scores and had good discriminant and content validity, internal consistency and test-retest reliability [17]. Thus, it was concluded that the WHOQOL-BREF provides a valid and reliable alternative assessment to the WHOQOL-100, with good discriminant validity of the domain profiles [17].

A review of scientific publications shows that the WHOQOL-BREF is widely used. This instrument has been psychometrically tested on adult patients with a broad range of diseases and health conditions, from a variety of inpatient and outpatient somatic and psychiatric healthcare facilities, and on healthy people from the general population [18-26]. Examples of studies where the WHOQOL-BREF has been used are on wounded, injured and ill patients from the military [24], persons with Parkinson disease [21], and those with HIV or AIDS [26]. We have found only few published studies in the literature using WHOQOL-BREF to measure the QOL of next of kin. Two studies used QOL as an outcome measure of an intervention, one with mindfulness training for 130 next of kin of palliative inpatients in Germany [23], and one on using a telephone-based support program for 55 next of kin of patients with dementia in USA (20). Three studies investigated predictors of QOL among next of kin in different contexts: patients with a disorder of consciousness in Italy [19], patients with psychiatric illnesses in Jordan [18] and older persons aged 80 years and above in Brazil [27]. However, these studies are not psychometric evaluations and no study has been conducted specifically on next of kin to older persons living in nursing homes. The only studies measuring the psychometric properties of WHOQOLBREF have been performed on patients [25, 28-30] and on the general population $[25,31]$. Furthermore, the Swedish version of WHOQOL-BREF has not previously been tested on next of kin to older persons in nursing homes, although it has been used as an outcome measure in an educational intervention in palliative care in the Swedish KUPA (knowledge-based palliative care) project [32]. When performing intervention studies it is vitally important to have valid and reliable instruments that are sensitive enough to measure changes and to ensure that the established dimensionality and factorloading pattern in WHOQOL-BREF fit the population in question in order to get reliable results. Accordingly, the purpose of this study was to investigate the psychometric properties of the WHOQOL-BREF among next of kin to older persons in nursing homes.

\section{Methods}

This study is designed as a cross-sectional study with psychometric evaluation based on classical test theory [32].

\section{Research setting of the KUPA project}

This study is part of a larger project of implementing palliative care in nursing homes, the KUPA project. In this project, an educational intervention for staff and 
managers is structured around the WHO definition of palliative care, which has been operationalized into four cornerstones: symptom relief for the patient, multiprofessional cooperation, continuous communication and support to the patient and the family. The goal of palliative care in the KUPA project is thus to address physical, psychosocial and spiritual needs as well as to provide support to the family [33, 34]. The WHOQOLBREF was used as the outcome measure for evaluating the impact of the intervention on the next of kin's QOL. This instrument was chosen because it has a clear theoretical basis for the concept of QOL [17]. The project involved 30 nursing homes for older persons in the Swedish counties of Kronoberg and Skåne [32]. They were situated in both urban and rural areas and included a mix of large nursing homes (with more than 100 residents) and smaller ones (with fewer than 25 residents). The project and the current study were approved by the regional ethical review board in Lund, Sweden (approval no.: 2015/4), with the trial registration number NCT02708498.

\section{WHOQOL-BREF}

The WHOQOL-BREF [17] consists of 24 items scored in four domains: physical health (7 items), psychological health (6 items), social relationships (3 items) and environment (8 items). The questionnaire also includes two items which are analysed separately: one question about overall assessment of QOL, and one about overall satisfaction with health. Each item has a 5-point response scale, and a higher score indicates better QOL. The domain score is calculated from the average score across the items in that domain.

The principal investigator of the KUPA project (second author GA) received permission to use the Swedish version of the WHOQOL-BREF by the WHO. The ethical review led to exclusion of one item, "How satisfied are you with your sex life?", because it was deemed to be an unethical intrusion into the participant's private life. This exclusion was also approved by the WHO.

\section{Procedure}

A contact person, who could be an assistant nurse, manager or administrator, at each nursing home was informed by a researcher about the study and its inclusion criteria and asked to make the initial contact with the next of kin. Those who fulfilled the inclusion criteria were informed about the study and then asked if they were interested in participating. Where this was the case, the contact person passed on the informal caregiver's name and telephone number to the researcher, who then called each one and provided further information about the project and this particular study before inviting them to participate. Those who agreed to participate received the coded questionnaires by post with written information about the study and instructions on how to fill out the questionnaire. The package also included a consent form to sign and two prepaid envelopes, so that the consent form and the questionnaire could be returned separately to the researcher.

\section{Participants}

The inclusion criterion for next of kin was having a relation to one of the residents, i.e., older persons living at the included nursing homes, but not necessarily being a family member. Additional inclusion criteria were that they had to be able to speak and understand Swedish, and did regularly visit the older person in the nursing home. The goal of recruitment was 5-10 participants per item, which means a total of 254 participants for this psychometric evaluation. Further individuals matching the inclusion criteria were invited to participate until 300 of them had given oral consent. This number was calculated on an expected dropout rate of 50 persons or $17 \%$. The selected number of participants per nursing home was related to the capacity of the institution, ranging from 18 participants at a large nursing home to five participants at a small one. The number of dropouts and the reasons for dropout are shown in Fig. 1. Thus, the final sample consisted of 254 participants with a mean age of 64 years $(\mathrm{SD}=9.7)$, mostly women $(n=191)$. Most participants $(75 \%)$ usually visited the older person at the nursing home once a week or more. For more information on socio-demographic characteristics, see Table 1.

\section{Data analysis}

Data analysis was conducted using IBM SPSS Statistics v.20 and IBM SPSS Amos v.25 (IBM Corp., Armonk, NY, USA). In a first step, negatively phrased items in WHOQOL-BREF (Q3, Q4 and Q25) were reversed (1 = $5,2=4,3=3,4=2,5=1)$. Two items - one question about overall QOL and one about overall health - were analysed separately.

\section{Validity}

Internal validity in terms of data quality and targeting was assessed by missing values, item response, and floor and ceiling effects. Floor and ceiling effects were determined from the proportion of responses at the minimum and maximum extremes of the scale, if less than $20 \%$ of responses [35] are the highest or lowest possible response option, then it can be assumed that the scale is capturing the full range of potential responses in the population and that changes over time can be detected [36]. The Kolmogorov-Smirnov test was used to assess normality at the item level. A statistically non-significant result $(p \geq 0.05)$ indicates normality [37]. Construct validity was estimated by correlating item 1: "How would 


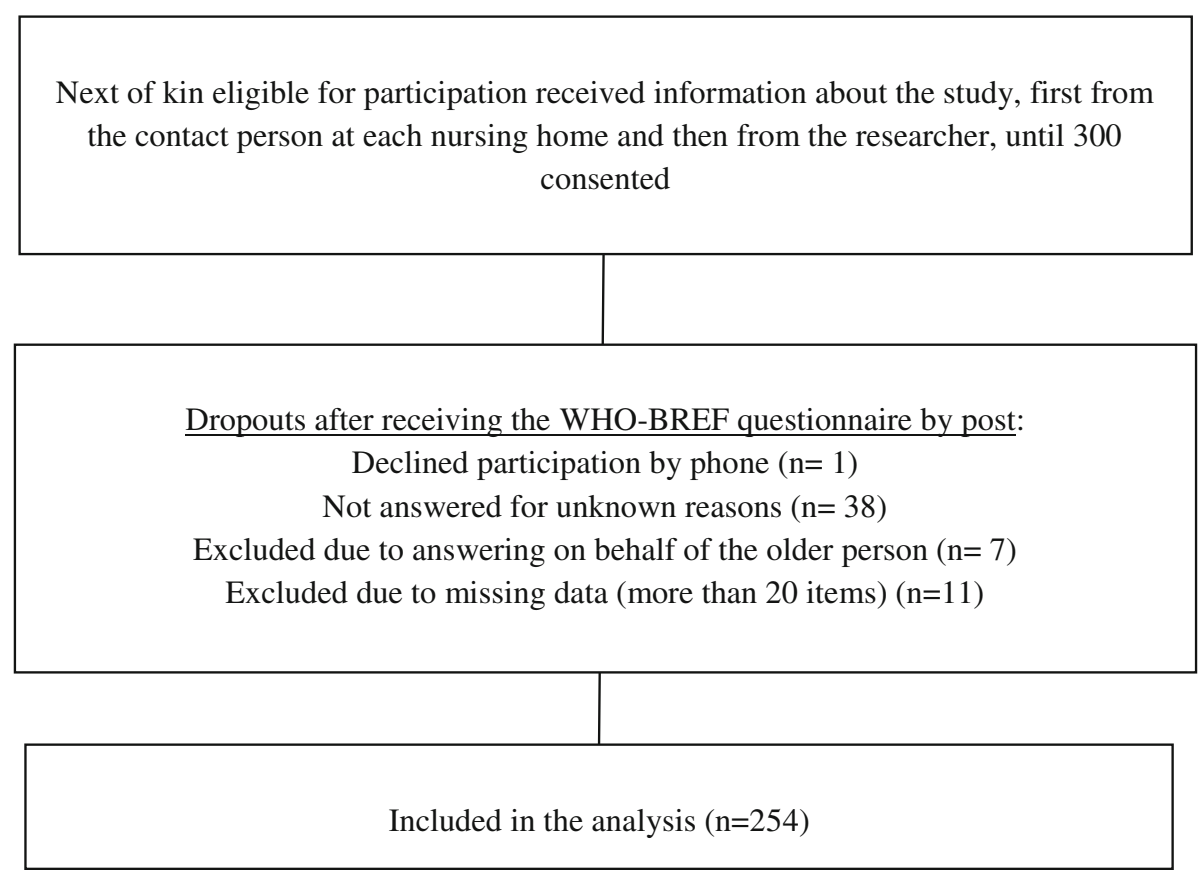

Fig. 1 Flow chart showing the inclusion procedure for the study participants

you rate your QOL?" and item 2: "How satisfied are you with your health?" with the four domains in the WHOQOL-BREF using Spearman's rank correlation.

\section{Reliability}

Internal consistency was assessed using Cronbach's alpha. To determine how closely each item correlates with the total score, corrected item-total correlations were calculated. The limit for satisfactory item correlation was set to $>0.30$. Values less than 0.30 indicate that the item is measuring something different from the scale as a whole [36].

\section{Factor structure}

The appropriateness of performing confirmatory factor analysis was checked according to quality criteria. These criteria were fulfilled by means of the Kaiser-MeyerOlkin measure of sampling adequacy (KMO-MSA) (0.90, should be 0.50 or above), Bartlett's test (0.01, should be $<0.05)$ and the determinant of the correlation matrix $(0.008$, should be $>0.00001)$ [38]. The number of cases per item was also calculated. Recommendations range from 2 to 20 subjects per item [39, 40], with an absolute minimum of 100 to 250 subjects [41-43]. Confirmatory factor analysis with maximum-likelihood estimation was applied to assess goodness of fit by means of various descriptive fit indices [44]. Specifically, the normed fit index (NFI), the comparative fit index (CFI) and the root mean squared error of approximation (RMSEA) were used [44].
The NFI equals the difference between the chi-square of the two models divided by the chi-square of the null model. An NFI over 0.90 is preferable. An NFI of .90 shows that the model of interest improves the fit by $90 \%$ in relation to the null model. CFI assesses fit relative to a null model and ranges from 0 to 1 , where values exceeding 0.95 are regarded as acceptable [45], CFI (0.99, 0.95, 0.92 and 0.90) distinguish between excellent, close, fair and mediocre or poor models respectively [46]. The RMSEA test assesses the lack of fit per degree of freedom of the model, "a cutoff value close to .06 for RMSEA are needed to conclude a relatively good fit between the hypothesized model and the observed data" [45](p.1). SPSS Amos only accepts data files with no missing values, which meant that 14 participants $(n=240)$ had to be excluded from the confirmatory factor analysis using listwise deletion [47].

\section{Results \\ Validity \\ Internal validity}

Overall, the rate of missing data was low and it was less than $2 \%$ for the majority of items. Of the 254 participants answered all 25 items. The Kolmogorov-Smirnov test showed a significant result at the item level $(p<$ 0.001 ), which indicates that the data were non-normally distributed. The floor effect ranged from 1 to $5 \%$ and the ceiling effect from 11 to $43 \%$; the ceiling effect was above $20 \%$ for 21 of 25 items (Table 2). 
Table 1 Socio-demographic and clinical characteristics of 254 study participants (next of kin to older persons in nursing homes)

\begin{tabular}{ll}
\hline Age, mean (SD) & $64(9.7)$ \\
\hline Gender, $n$ (\%) & $63(25)$ \\
Men & $191(75)$ \\
Women & \\
Civil status, $n$ (\%) & $205(81)$ \\
Married/cohabiting & $42(17)$ \\
Divorced/single/living alone & $6(2)$ \\
Widow/widower & \\
Relation, $n$ (\%) & $38(15)$ \\
Wife & $192(77)$ \\
Child & $4(2)$ \\
Sibling & $1(1)$ \\
Grandchild & $1(1)$ \\
Friend & $10(4)$ \\
Other & \\
Highest educational level, $n$ (\%) & $51(20)$ \\
Compulsory school & $62(25)$ \\
Upper secondary school & $41(16)$ \\
Vocational qualification & $97(39)$ \\
University degree or equivalent & \\
Employed, $n$ (\%) & $104(41)$ \\
No & $55(22)$ \\
Yes, part time & $36(37)$ \\
Ves, full time & \\
A couple of times per year & \\
Once a month or more & $167(67)$ \\
Once a week or more & $21(9)$ \\
\hline Every day & \\
\hline
\end{tabular}

\section{Construct validity}

Statistically significant positive correlations were found between how the participants rated their overall QOL (item 1) and the four domains in the WHOQOL-BREF instrument (physical health: $\mathrm{r}_{\mathrm{s}}=0.65, p<0.001$; psychological health: $\mathrm{r}_{\mathrm{s}}=0.67, p<0.001$; social relations: $\mathrm{r}_{\mathrm{s}}=$ $0.44, p<0.001$; environment: $\left.\mathrm{r}_{\mathrm{s}}=0.57, p<0.001\right)$. Significant correlations were also found between how the participants rated overall satisfaction with their health (item 2) and the four WHOQOL-BREF domains (physical health: $\mathrm{r}_{\mathrm{s}}=0.73, p<0.001$; psychological health: $\mathrm{r}_{\mathrm{s}}=0.62$, $p<0.001$; social relations: $\mathrm{r}_{\mathrm{s}}=0.44, p<0.001$; environment: $\left.\mathrm{r}_{\mathrm{s}}=0.49, p<0.001\right)$.

\section{Reliability}

\section{Internal consistency}

The Cronbach's alpha of the total instrument was 0.83 , indicating satisfactory internal consistency for the overall scale. Table 3 shows the results of the four subscales. The corrected item-total correlations within each scale varied between 0.35 and 0.68 and were thus well above the lower limit of 0.30 .

\section{Factor structure}

The overall measure of sampling adequacy, using the KMO test, for the WHOQOL-BREF matrix was .90, which is a clear indication that data was appropriate for factor analysis. Additionally, Bartlett's statistic showed a $p$-value $<0.05$ (Bartlett's statistic $=2916, \mathrm{df}=253, p=$ 0.01 ), and the number of cases (participants) per item was calculated at 11 , in line with the recommendations of 5-10 cases per item [48]. The confirmatory factor analysis showed that the chi-square for the model was significant, indicating an unacceptable model fit. However, according to the CFI, a large amount of the variance was accounted for $(\mathrm{CFI}=.93)$, indicating a fair to close model fit. Additionally, an RMSEA value of .06 indicated a good model fit and demonstrated that several significant relations were accounted for (Tables 4 and 5).

\section{Discussion}

The literature shows that our study is the first published paper to investigate the psychometric properties of the Swedish version of WHOQOL-BREF on next of kin to older persons in nursing homes. The results showed that the WHOQOL-BREF dimensionality and factor-loading pattern fits the group and that the measured variables represent the QOL construct in the group. However, a notable ceiling effect may restrict the ability of the WHOQOL-BREF to detect positive changes in QOL over time among next of kin to older persons in nursing homes.

\section{Validity}

\section{Internal validity}

The quality of the data in this study can be assumed to be satisfactory with regard to the number of participants, $n=240$, when compared to other psychometric studies performed on similar instruments. For example, in another study using the WHOQOL-BREF among 130 next of kin to patients receiving palliative care [23], the number of respondents can be regarded as the weakness in that study, given the recommendation to have 2-20 participants per item when performing factor analysis [38, 39]. However, many published studies have failed to justify their sample size determination, [48], which highlights the need for clear, scientifically sound recommendations on the topic of optimal study samples when using factor analysis in this kind of study.

The notable ceiling effect of over $20 \%$ in 21 of the 25 WHOQOL-BREF items in this study might pose an obstacle when using these items as outcome measures in 
Table 2 Data quality of the WHOQOL-BREF used with next of kin to persons in nursing homes $(N=254)$

\begin{tabular}{|c|c|c|c|c|c|c|}
\hline Items & $\mathrm{N}$ & Mean (SD) & Median & Missing (\%) & Floor (\%) & Ceiling (\%) \\
\hline 1. Overall assessment of QOL & 253 & $4.2(.81)$ & 4 & 0.004 & 0 & 38 \\
\hline 2. Overall satisfaction with health & 253 & $3.9(.88)$ & 4 & 0.004 & 1 & 23 \\
\hline 3. Pain & 254 & $4.2(.81)$ & 2 & 0 & 2 & 43 \\
\hline 4. Medication & 254 & $3.9(.88)$ & 2 & 0 & 5 & 43 \\
\hline 5. Positive feelings & 254 & $2.0(1.1)$ & 4 & 0 & 1 & 28 \\
\hline 6. Spirituality & 254 & $4.1(.80)$ & 4 & 0 & 1 & 32 \\
\hline 7. Thoughts & 253 & $3.8(.71)$ & 4 & 0.004 & 5 & 11 \\
\hline 8. Safety & 254 & $4.1(.68)$ & 4 & 0 & 2 & 24 \\
\hline 9. Environment & 253 & $4.0(.63)$ & 4 & 0.004 & 3 & 21 \\
\hline 10. Energy & 254 & $3.8(.89)$ & 4 & 0 & 1 & 42 \\
\hline 11. Body image & 254 & $3.9(.81)$ & 4 & 0 & 0 & 48 \\
\hline 12. Finances & 252 & $4.1(.94)$ & 4 & 0.008 & 2 & 38 \\
\hline 13. Information & 254 & $4.3(.67)$ & 4 & 0 & 1 & 39 \\
\hline 14. Leisure & 254 & $3.8(.97)$ & 4 & 0 & 2 & 42 \\
\hline 15. Mobility & 254 & $4.3(.74)$ & 4 & 0 & 2 & 42 \\
\hline 16. Sleep & 253 & $3.8(1.0)$ & 4 & 0.004 & 1 & 28 \\
\hline 17. Activities & 253 & $4.0(.84)$ & 4 & 0.004 & 0 & 30 \\
\hline 18. Work & 252 & $3.9(.81)$ & 4 & 0.008 & 3 & 25 \\
\hline 19. Self-esteem & 254 & $4.1(.65)$ & 4 & 0 & 0 & 24 \\
\hline 20. Relationships & 249 & $4.3(.66)$ & 4 & 0.020 & 0 & 34 \\
\hline 21. Support & 251 & $4.2(.70)$ & 4 & 0.010 & 0 & 32 \\
\hline 22. Home & 251 & $4.5(.63)$ & 5 & 0.010 & 1 & 56 \\
\hline 23. Services & 250 & $4.1(.80)$ & 4 & 0.020 & 1 & 29 \\
\hline 24. Transport & 248 & $4.2(.88)$ & 4 & 0.020 & 2 & 38 \\
\hline 25. Negative feelings & 251 & $2.1(.76)$ & 2 & 0.010 & 1 & 17 \\
\hline
\end{tabular}

clinical trials among next of kin to older persons in nursing homes. These items might underestimate actual changes and differences between study participants in this context [49]. The recommended maximum ceiling and floor effect varies in different publications, but a ceiling or floor effect is usually defined as $15 \%$ or more [35]. A notable ceiling effect can make changes or differences detectable only in one direction [50]. This characteristic means that most items in the WHOQOL-BREF might only measure negative changes, not positive ones, among next of kin to older persons in nursing homes. One explanation for the high ceiling effect might be the sample homogeneity in age and gender [36]. QOL has, in previous research, shown to vary according to age and sex [51]. In this study, the mean age was 64 years $( \pm 9.7)$, and $76 \%$ of the sample were women, which may have contributed to the high QOL scores. The Swedish National Board of Health and Welfare [51] has demonstrated

Table 3 Internal consistency for each domain in WHOQOL-BREF in relation to previous psychometric testing of WHOQOL-100 and WHOQOL-BREF

\begin{tabular}{llll}
\hline Domain & $\begin{array}{l}\text { Swedish WHOQOL-BREF }(N=254) \\
\text { Cronbach's alpha }\end{array}$ & $\begin{array}{l}\text { WHOQOL-BREF } \\
\text { Cronbach's alpha }\end{array}$ & $\begin{array}{l}\text { WHOQOL-100 } \\
\text { Cronbach's alpha }^{\text {Clphas }}\end{array}$ \\
\hline Physical & .86 & .80 & .86 \\
Psychological & .82 & .76 & .82 \\
Social relationships & $.77^{\mathrm{b}}$ & .66 & .73 \\
Environment & .80 & .85 & .85 \\
\hline
\end{tabular}

${ }^{\mathrm{a}}$ The WHO-Group (1998)

${ }^{b}$ Only two items, therefore Cronbach's alpha may not be reliable 
Table 4 The model statistics of the confirmatory factor analysis of the WHOQOL-BREF when applied to next of kin of older persons in nursing homes $(n=240)$

\begin{tabular}{llllll}
\hline Statistics & $X^{2}$ & df & $P$ & CFI & RMSEA \\
\hline Model fit for WHOQOL-BREF with four dimensions & 405.738 & 207 & .001 & .926 & .063 \\
\hline$X^{2}$ Chi-sq
\end{tabular}

$X^{2}$ Chi-square goodness of fit, $d f$ degrees of freedom, CFI comparative fit index, RMSEA root mean square error of approximation

that it is primarily next of kin aged $30-44$ years who are more adversely affected by providing care. In that study, up to $74 \%$ of the next of kin experienced the commitment of providing this care as psychologically stressful. Additionally, the results also showed that it is more common for female than male caregivers to experience psychological stress, which contradicts our results [51]. The likely explanation for this discrepancy is that in our study, the women were significantly older and in a different phase of life. Caregivers over the age of 64 and those between 18 and 29 reported stress to a much lower extent. Therefore, if our study had included next of kin in the 30-44 age group, the ceiling effect might not have been so high. Accordingly, there is a need for further research on the psychometric properties of the WHOQOL-BREF among a more mixed group of next of kin to older persons in nursing homes, including those aged $30-44$ years.

\section{Construct validity}

Overall, the result indicates good construct validity of the WHOQOL-BREF. Each domain in the instrument correlated with the participants' ratings on overall QOL and satisfaction with health, constructs that are theoretically similar. However, these results should be interpreted with some caution because the instrument is based on an ordinal scale without equidistant measurement points, in line with Streiner's recommendations on the development and use of health measurement scales [36].

\section{Reliability}

Internal consistency

The internal consistency for each domain is in line with previous psychometric testing of the WHOQOL-100 and the WHOQOL-BREF (Table 3) and studies

Table 5 Factor loadings in confirmatory factor analysis for WHOQOL-BREF

\begin{tabular}{|c|c|c|c|c|}
\hline \multirow[t]{2}{*}{ WHOQOL-BREF items } & \multicolumn{4}{|c|}{ WHOQOL-BREF domains } \\
\hline & Physical & Psychological & Social relationships & Environment \\
\hline (3) Pain & 0.62 & & & \\
\hline (10) Energy & 0.85 & & & \\
\hline (16) Sleep & 0.47 & & & \\
\hline (15) Mobility & 0.61 & & & \\
\hline (17) Activity & 0.89 & & & \\
\hline (4) Medication & 0.54 & & & \\
\hline (18) Work & 0.83 & & & \\
\hline (5) Positive feelings & & 0.70 & & \\
\hline (7) Think & & 0.61 & & \\
\hline (19) Esteem & & 0.70 & & \\
\hline (11) Body esteem & & 0.55 & & \\
\hline (25) Negative feelings & & 0.59 & & \\
\hline (6) Spirituality & & 0.71 & & \\
\hline (20) Relationships & & & 0.81 & \\
\hline (21) Support & & & 0.77 & \\
\hline (8) Safety & & & & 0.73 \\
\hline (22) Home & & & & 0.53 \\
\hline (12) Finances & & & & 0.47 \\
\hline (23) Services & & & & 0.45 \\
\hline (13) Information & & & & 0.51 \\
\hline (14) Leisure & & & & 0.75 \\
\hline (9) Environment & & & & 0.61 \\
\hline (24) Transport & & & & 0.34 \\
\hline
\end{tabular}


previously conducted on the WHOQOL-BREF in a different context [17]. A Cronbach's alpha of 0.83 indicated satisfactory internal consistency in line with the study by Dalky and colleagues [52], whose results showed satisfactory Cronbach's alpha $(\geq 0.70)$ and item-internal consistency $(\geq 0.40)$. Taken together, based on the results of our study in comparison with previously conducted studies, the variables that comprise the scale can be assumed to measure the same underlying construct. However, when Cronbach's alpha coefficients were calculated separately for the four WHOQOL-BREF domains, high values for Cronbach's alpha only showed good internal consistency for three out of four domains. One weakness is that the social relationships domain includes very few items: in the original instrument, it included three items, and in our study, it included only two items after the question "How satisfied are you with your sex life?" was excluded. It might therefore be questioned whether the high total Cronbach's alpha coefficient observed for the entire scale can be interpreted as indicating a unidimensional measure [53]. However, the corrected item-total correlations were well above the limit of 0.30 [36], indicating that the items are measuring the same underlying construct.

\section{Factor structure}

According to the confirmatory factor analysis, a large amount of the variance was accounted for $(\mathrm{CFI}=.93)$, indicating a fair to close model fit [44]. Additionally, the RMSEA value of 06 indicated good model fit and that several significant relations were accounted for (Table 4).

The chi-square for the model, however, was significant, indicating an unacceptable model fit. Nonetheless, chi-square goodness of fit has been shown to be sensitive to sample size: the larger the sample size is, the more likely a model will fail to fit when using the chisquare goodness-of-fit measure. Consequently, many researchers disregard this index if the sample size is more than 200 and the other indices indicate that the model is acceptable [54]. In addition, CFI and RMSEA have been shown to be less sensitive to sample size [54]. Based on the result of the factor analysis and in keeping with recommendations for interpreting factor analysis [55], we cautiously interpret the model structure as having a fair to close model fit. Nevertheless, the result of the WHOQOL-BREF factor analysis must be interpreted in the light of the fact that "no confirmatory factor analysis model should be accepted on statistical grounds alone; theory, judgement, and persuasive argument should play a key role in defending the adequacy of any estimated confirmatory factor analysis model" [56] (p. 554).

\section{Validity and reliability in relation to other settings}

In addition to the two intervention studies from Germany and USA, studies on next of kin and have been conducted in Brazil, Italy and Jordan, three countries with a large cultural distance from Sweden [18, 27]. This makes it difficult to compare these results with the results of the present study on next of kin. Firstly, in those countries, the younger generation in the family is traditionally obligated to take care of older family members, whereas in Sweden this care is based on a social welfare system without formal responsibility for the older generation compared with countries where the family is obligated formally. Secondly, no study has included next of kin to older person with multiple morbidities living in a nursing home. Thirdly, the most common psychometric data in these studies are missing or based on a small sample.

\section{Study strengths and limitations}

The study has some strengths and limitations. One strength is that the WHOQOL-BREF is based on a thorough theory and definition, and another is that the participants were recruited from 30 nursing homes, both large and small. However, issues related to our data might limit the findings. The domain of social relationships was not examined completely, as the Swedish ethical review board decided to exclude one of the questions. Another study limitation might be that the CFI value of 0.93 is lower than the recommended value of 0.95 for goodness of fit [46]. However, RMSEA showed good model fit and several significant relations were accounted for and the result of CFI was relatively close to the recommended value. Based on this and in line with the recommendations of Marcoulides and Yuan [46] we conclusively conclude that the model has a fair fit when used among next of kin to older persons in nursing homes. Additionally, the present study's CFI value of 0.93 is higher than the CFI of 0.90 found in the original psychometric study of WHOQOL-BREF [17]. Another limitation was, as discussed above, the homogeneous sample. Furthermore, confirmatory factor analysis with maximum-likelihood estimation used in this study to enable comparison of the results with previously conducted studies does not take ordinal data into account, which may have affected the results. However, according to Cheng-Hsien Li [57] ignoring the ordinal nature of the data when using the maximum-likelihood estimation may affect the results by yielding underestimation of factor loadings. In turn, this can reduce precision and accuracy of the model, which can lead to misleading conclusions. The fewer participants in the study, the greater the risk of underestimation, but in our study the sample size was relatively large $(N=254)$. Maximumlikelihood estimation is best fitted when the latent 
distributions are non-normal with a sample size of $N=$ 200 [57]. Furthermore, Likert scales, as in WHOQOLBREF, can be treated as interval data to allow parametric statistics such as correlational analyses, factor analysis and analysis of variance to be used as long as all other design conditions and assumptions are met [58].

\section{Conclusion}

The findings suggest that the WHOQOL-BREF instrument may constitute a reliable and valid measure of QOL for next of kin to older persons in nursing homes. The results of this study imply some uncertainty, since the ability of the instrument to detect changes in QOL over time is constrained by the percentage of respondents responding at the ceiling or floor level of the scale. There is a need to assess whether the WHOQOL-BREF reliably represents and measures QOL in a broader age group of next of kin to older persons in nursing homes.

\section{Abbreviations}

CFI: Comparative fit index; KMO: Kaiser-Meyer-Olkin; KUPA: KUnskapsbaserad PAlliativ vård (knowledge-based palliative care); QOL: Quality of life; RMSEA: Root mean square error of approximation; WHO: World Health Organization; WHOQOL-100: World Health Organization Quality of Life-100; WHOQOL-BREF: World Health Organization Quality of Life (abbreviated)

\section{Acknowledgements}

The authors thank the study participants who made this study possible. This work was supported by: the Swedish Research Council, grant number 2014 2759; the Varrdal Foundation, grant number 2014-0071; and the Faculty of Medicine at Lund University. We also thank Albert Westergren for his valuable review of the manuscript based on his expert knowledge of psychometry.

\section{Author details}

HR has a position as Assistant University Lecturer at the Department of Health Sciences, Lund University. She is registered nurse specialist by training and have her background in the field of the intensive care and anaesthesia care.

GA is registered nurse and has a position as Professor at the Department of Health Sciences, Lund University. She has long experiences as PI of different research project with different design including elderly care and next of kin to older persons.

AL has a position as Assistant University Lecturer at the Department of Health Sciences, Lund University. She is registered occupation therapist by training and have her background in the mental health care field.

\section{Authors' contributions}

AL was the study supervisor and contributed to all aspects of the study. HR and $A L$ were the main investigators and provided the first draft. GA is the PI of the KUPA project and was study advisor and contributed to the study design, critically reviewed the paper and contributed to the final draft. AL and HR contributed to the writing process. All authors read and approved the final manuscript.

\section{Funding}

Open access funding provided by Lund University.

\section{Availability of data and materials}

The data generated during the project and analysed in this study are not publicly available due to the inclusion of sensitive information regarding a vulnerable group, older persons living in nursing homes. The regional ethical review board in Lund set limitations regarding accessibility of the data. Therefore, before approving access to data, the principal researcher (GA) of the KUPA project must consult with the review board.

\section{Ethics approval and consent to participate}

The project and the included studies were approved by the Regional Ethical Review Board, Lund, Sweden (approval number: 2015/4), trial registration: NCT02708498.

\section{Consent for publication}

Not applicable.

\section{Competing interests}

The authors declare that they have no competing interests.

Received: 14 January 2019 Accepted: 1 April 2020

Published online: 19 April 2020

\section{References}

1. Meinow B, et al. Complex health problems in the oldest old in Sweden 1992-2002. J Eur J Ageing. 2006;3(2):98-106.

2. Eika $M$, et al. Experiences faced by next of kin during their older family members' transition into long-term care in a Norwegian nursing home. J Clin Nurs. 2014;23:15-6. https://doi.org/10.1111/jocn.12491

3. Alice Lau WY, et al. Institutionalized elders with dementia: collaboration between family caregivers and nursing home staff in Taiwan. J Clin Nurs. 2008:17(4):482-90.

4. Davies S, Nolan M. 'Making the move': relatives' experiences of the transition to a care home. J Health Soc Care Commun. 2004;12(6):517-26.

5. Hertzberg A, Ekman S. 'We, not them and us?' views on the relationships and interactions between staff and relatives of older people permanently living in nursing homes. J Adv Nurs. 2000;31(3):614-22.

6. Lundh, U., J. Sandberg, And M. Nolan, 'I don't have any other choice': spouses' experiences of placing a partner in a care home for older people in Sweden. J Adv Nurs, 2000. 32(5): p. 1178-1186.

7. Kontis $\mathrm{V}$, et al. Future life expectancy in 35 industrialised countries: projections with a Bayesian model ensemble. Lancet. 2017;389(10076):1323-

8. WHO. Ageing Health. 2018 [cited 2019 September 23]

9. Wallerstedt $B$, et al. Striking a balance: a qualitative study of next of kin participation in the Care of Older Persons in nursing homes in Sweden. Healthcare. 2018:6(2):46.

10. Høgsnes $L$, et al. The existential life situations of spouses of persons with dementia before and after relocating to a nursing home. Aging Ment Health. 2014:18(2):152-60.

11. Yıkılkan H, Aypak C, Görpelioğlu S. Depression, anxiety and quality of life in caregivers of long-term home care patients. Arch Psychiatr Nurs. 2014;28(3): 193-6.

12. Andersson $\mathrm{M}$, et al. The experience of being next of kin to an older person in the last phase of life. Palliat Supp Care. 2010;8(1):17-26. https://doi.org/10. 1017/S1478951509990666.

13. The WHOQOL Group. The World Health Organization quality of life assessment (WHOQOL): position paper from the World Health Organization. Soc Sci Med. 1995;41(10):1403-9.

14. Hall S, et al. Palliative care for older people: better practices. Copenhagen: WHO Regional Office for Europe; 2011. https://apps.who.int/iris/bitstream/ handle/10665/107290/e95052.pdf.

15. Håkanson C, et al. A population-level study of place of death and associated factors in Sweden. J Scand J Public Health. 2015;43(7):744-51.

16. Power M, Bullinger M, Harper A. The World Health Organization WHOQOL100: Tests of the universality of quality of life in 15 different cultural groups worldwide. Am Psychol Assoc. 1999. https://doi.org/10.1037/0278-6133.18.5. 495.

17. The WHOQOL Group. Development of the World Health Organization WHOQOL-BREF quality of life assessment. Psychol Med. 1998;28(3).

18. Dalky $\mathrm{H}$, et al. Quality of life, stigma and burden perception among family caregivers and patients with psychiatric illnesses in Jordan. Comm Ment Health J. 2017:53(3):266-74.

19. DeGregory C. The effects of multiple gratitude interventions among informal caregivers of persons with dementia and Alzheimer's disease: University of South Carolina; 2014. p. 148.

20. Giovannetti AM, et al. Caregivers of patients with disorder of consciousness: burden, quality of life and social support. Acta Neurol Scand. 2015;132(4): 259-69. 
21. Hendred SK, Foster ER. Use of the World Health Organization Quality of Life Assessment Short Version in Mild to Moderate Parkinson Disease...2016 ACRM / American Congress of Rehabilitation Medicine Annual Conference 30 October - 4 November 2016, Chicago, IL. Arch Phys Med Rehabil. 2016; 97(12):2123-2129.e1.

22. Jadalla A, Mamier I. Quality of Life, Depression, and Burden of Care Among Caregivers of Patients With Hematologic Cancers...Middle Eastern Nurses Uniting in Human Caring, Third Annual Middle East Conference; Aqaba, Jordan, February 2015. Int J Hum Caring. 2015;19(4):79.

23. Kögler $\mathrm{M}$, et al. Mindfulness in informal caregivers of palliative patients. Palliat Support Care. 2015;13(1):11-8.

24. Lindsay $\mathrm{K}$, et al. Psychometric properties of the WHOQOL-BREF amongst wounded, injured, and ill members of the United States military. Ment Health Rev J. 2017;22(2):124-35

25. Lucas-Carrasco R. The who quality of life (WHOQOL) questionnaire: Spanish development and validation studies. Qual Life Res. 2012;21(1):161-5.

26. Yu Y, et al. Psychometric testing of the Chinese version of the medical outcomes study social support survey among people living with HIV/AIDS in China. Appl Nurs Res. 2015;28(4):328-33.

27. Silva Coura A, et al. Quality of life of caregivers of octogenarians: a study using the WHOQOL-BREF. Invest Educ Enferm. 2015:33(3):529-38.

28. Berlim MT, et al. Reliability and validity of the WHOQOL BREF in a sample of Brazilian outpatients with major depression. J Qual Life Res. 2005;14(2):561-4.

29. Naumann VJ, Byrne GJ. WHOQOL-BREF as a measure of quality of life in older patients with depression. J Int Psychogeriatr. 2004;16(2):159-73.

30. Yang S-C, et al. Quality of life and its determinants of hemodialysis patients in Taiwan measured with WHOQOL-BREF (TW). J Am J Kidney Dis. 2005; 46(4):635-41.

31. World Health Organization. Programme on mental health: WHOQOL user manual: World Health Organization; 1998.

32. Ahlström G, et al. Implementation of knowledge-based palliative care in nursing homes and pre-post post evaluation by cross-over design: a study protocol. BMC Palliat Care. 2018;17(1):52. https://doi.org/10.1186/s12904-0180308-2.

33. World Health Organization. Strengthening of palliative care as a component of integrated treatment throughout the life course. J Pain Palliat Care Pharmacother. 2014;28(2):130-4.

34. World Health Organization. Why palliative care is an essential function of primary health care (No. WHO/HIS/SDS/2018.39). World Health Organization. 2018.

35. McHorney CA, Tarlov AR. Individual-patient monitoring in clinical practice: are available health status surveys adequate? Qual Life Res. 1995;4(4):293307.

36. Streiner DL, Norman GR, Cairney J. Health measurement scales: a practical guide to their development and use. 5th ed. Oxford: Oxford Univerity Press; 2014.

37. Massey FJ. The Kolmogorov-Smirnov test for goodness of fit. J Am Stat Assoc. 1951;46(253):68-78.

38. Dziuban CD, Shirkey EC. When is a correlation matrix appropriate for factor analysis? Some decision rules. Psychol Bull. 1974;81(6):358-61.

39. Lai K, Kelley K. Accuracy in parameter estimation for targeted effects in structural equation modeling: sample size planning for narrow confidence intervals. Psychol Methods. 2011:16(2):127-48.

40. Lomas J, Pickard L, Mohide A. Patient versus clinician item generation for quality-of-life measures: the case of language-disabled adults. Med Care. 1987;25(8):764-9.

41. Everitt BS. Multivariate analysis: the need for data, and other problems. Br J Psychiatry. 1975;126(3):237-40.

42. Gorsuch RL. Factor analysis. 2nd ed. Hillsdale: Lawrence Erlbaum Associates; 1983.

43. Cattell R. In: Springer, editor. The Scientific Use of Factor Analysis in Behavioral and Life Sciences. Boston: Springer; 1978. p. 618.

44. Schermelleh-Engel, K. and H. Moosbrugger, Evaluating the fit of structural equation models: tests of significance and descriptive goodness-of-fit measures. Methods Psychol Res Online, 2003. 8(2).

45. Hu Lt, Bentler PM. Cutoff criteria for fit indexes in covariance structure analysis: Conventional criteria versus new alternatives. Struct Equ Model Multidiscip J. 1999;6(1):1-55.

46. Marcoulides KM, Yuan K-H. New ways to evaluate goodness of fit: a note on using equivalence testing to assess structural equation models. Struct Equ Model Multidiscip J. 2017;24(1):148-53.
47. Arbuckle JL. IBM ${ }^{\oplus}$ SPSS $^{\oplus}$ Amos $^{\text {TM }} 26$ User's guide IBM Corp; 2017.

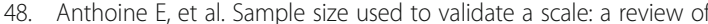
publications on newly-developed patient reported outcomes measures. Health Qual Life Outcomes. 2014;12:176.

49. Baron $\mathrm{R}$, et al. Measuring outcomes in cervical spine surgery: think twice before using the SF-36. Spine. 2006;31(22):2575-84

50. Hagell P, Törnqvist AL, Hobart J. Testing the SF-36 in Parkinson's disease. J Neurol. 2008;255(2):246-54

51. National Board of Health and Welfare. Socialstyrelsen: Stöd till personer som vårdar och stödjer närstående. Slutrapport 2014 [Support for informal caregivers. Final report 2014] 2014 [cited 8 december 2018; 78]. Available from: https://www.socialstyrelsen.se/globalassets/sharepoint-dokument/ artikelkatalog/statistik/2014-12-6.pdf.

52. Dalky HF, Meininger JC, Al-Ali NM. The reliability and validity of the Arabic World Health Organization quality of life-BREF instrument among family caregivers of relatives with psychiatric illnesses in Jordan. J Nursing Res. 2017;25(3):224-30.

53. Nikkhah $\mathrm{M}$, et al. Psychometric properties the Iranian version of older People's quality of life questionnaire (OPQOL). Health Qual Life Outcomes. 2018;16(1):174.

54. Tanguma J. Effects of sample size on the distribution of selected fit indices: a graphical approach. Educ Psychol Meas. 2001:61(5):759-76.

55. Jackson DL, Gillaspy JA Jr, Purc-Stephenson R. Reporting practices in confirmatory factor analysis: an overview and some recommendations. Psychol Methods. 2009;14(1):6-23.

56. Reise SP, Widaman KF, Pugh RH. Confirmatory factor analysis and item response theory: two approaches for exploring measurement invariance. Psychol Bull. 1993;114(3):552-66.

57. Li C-H. Confirmatory factor analysis with ordinal data: comparing robust maximum likelihood and diagonally weighted least squares. Behav Res Methods. 2016:48(3):936-49.

58. Brown JD. Likert items and scales of measurement. Shiken JALT Test Eval SIG Newsletter. 2011;15(1):10-4.

\section{Publisher's Note}

Springer Nature remains neutral with regard to jurisdictional claims in published maps and institutional affiliations.

Ready to submit your research? Choose BMC and benefit from

- fast, convenient online submission

- thorough peer review by experienced researchers in your field

- rapid publication on acceptance

- support for research data, including large and complex data types

- gold Open Access which fosters wider collaboration and increased citations

- maximum visibility for your research: over $100 \mathrm{M}$ website views per year

At $\mathrm{BMC}$, research is always in progress.

Learn more biomedcentral.com/submissions 